\title{
An Atypical Presentation of HELLP Syndrome
}

\author{
Dr Devi Prasad Pradhan*,Dr Suchismita Panda** \\ * Senior Resident,Department Of Biochemistry,SCB Medical College,Cuttack \\ ** Assistant Professor, Department Of Biochemistry,SCB Medical College,Cuttack
}

\begin{abstract}
Background: HELLP syndrome, named for 3 features of the disease (hemolysis, elevated liver enzyme levels, and low platelet levels), is a life-threatening condition that can potentially complicate pregnancyTypically occurs between 27 weeks' gestation and with wide range of symptoms, such as nausea, vomiting, epigastric and right upper quadrant pain none of which are diagnostic has been reported in 30\%-90\%of patients, headache in 33\%-68\%,visual changes in 10\%-20\% and jaundice in 5\%.The disease process is often associated with maternal complications such as DIC,myocardial ischaemia, pulmonary edema,haemorrhagic stroke,acute renal failure andneonatal complications such as prematurity,intrauterine growth retardation and thrombocytopenia.Such a condition shold be identified and treated urgently.
\end{abstract}

\section{Introduction}

This case is about a 32 year old multiparous who attended emergency with complains of 2-3 episodes of vomiting.She was pregnant by 8 months.Clinical examination did not reveal any significant abnormality except for mild tenderness in the epigastric region.Routine investigations were within reference range.The Gynaecologist treated the case as of gastritis with I.V pantoprazole and I.V ondansetron.The condition of the patient deteriorated next day morning when she developed 7 episodes of convulsions.Immediate termination of pregnancy was advised.During the intraoperative period,the condition of the patient further deteriorated due to severe bleeding without any injury to major vessels.Blood sample was sent for further investigations which revealed a very low haemoglobin $(2 \mathrm{gm} \%)$,elevated liver enzymes with elevated bilirubin ( T.Bil $-2.1 \mathrm{mg} \%, \mathrm{D}$ Bil - 1mg\%,SGOT - $4600 \mathrm{IU} / \mathrm{l}, \mathrm{SGPT}-5400 \mathrm{IU} / 1, \mathrm{ALP}-880 \mathrm{IU} / \mathrm{l}$ ) and a very low platelet count ( less than $16,000 /$ cumm).Serum LDH was also very high and gross proteinuria was present.The case was diagnosed to be a case of HELLP syndrome and treated accordingly and luckily the patient survived.

This variable nature of clinical presentation generally delays the diagnosis of HELLP syndrome for an average of 8 days ${ }^{(1)}$.Patients with this disorder are often misdiagnosed with other disorder such as cholecystitis,esophagitis, gastritis, hepatitis or ITP.(2)

HELLP syndrome named for three features like hemolysis,elevated liver enzymes and low platelet count is life threatening condition that can potentially complicate pregnancy.Although some propose that HELLP syndrome is a severe form of Pre-eclampsia,others believe that HELLP syndrome is an entity of its own (3). HELLP syndrome occurs in $0.1 \%-0.6 \%$ of all pregnancies and in $4 \%-12 \%$ of patients with preeclampsia. Multiparity,maternal age greater than 35 years, white race and history of poor pregnancy outcome are the known associated risk factors ${ }^{(4)}$.

The pathophysiology of HELLP syndrome is ill defined.Probably it starts from defective placental vascular remodelling during $16-22$ wks of gestation,resulting in release of placental factors such as Soluble Vascular Endothelial Growth Factor Receptor -1 (SVEGR-1) and placental growth factor which binds vasculoendothelial growth factor(VEGF).This prevents the growth factors to bind to the endothelial cell receptors, resulting in endothelial and placental dysfunction ${ }^{(5)}$. The coagulation cascade gets activated,resulting in consumption of platelets due to adhesion into a damaged and activated endothelium. The erythrocytes also get destroyed as they traverse through the capillaries laden with platelet fibrin deposits leading to microangiopathic haemolytic anaemia.

Several other hypothesis includes acute maternal immune rejection due to immunocompetent maternal cells coming in contact with genetically distinct fetus altering the immune balance and causing endothelial dysfunction,platelet activation and aggregation and hypertension ${ }^{(6,7,8)}$.

The vague presentation in HELLP syndrome in patients with nausea,vomiting, malaise, headache prevents the early diagnosis of the disease process.

Diagnostic tests of this condition includes decreased haptoglobin level to detect the ongoing haemolysis,raised transaminases level,low to very low platelet count. Also a positive D-dimer test is most sensitive indicator of subclinical coagulopathy and may be positive before coagulation studies are abnormal.

Prompt recognition of HELLP syndrome and timely initiation of treatment are vital to ensure favourable maternal and fetal outcome. The recurrence rate is $2 \%-27 \%$ in subsequent pregnancies ${ }^{(9,10)}$.Patients with HELLP syndrome should be educated on the risk of maternal and fetal morbidity and mortality in future pregnancies. 


\section{References}

[1]. Schroder W, Heyl W. HELLP-syndrome. Difficulties in diagnosis and therapy of a severe form of preeclampsia. Clin Exp Obstet Gynecol. 1993;20:88-94.

[2]. Wolf JL. Liver disease in pregnancy. Med Clin North Am. 1996;80:1167-87.

[3]. Rath W, Faridi A, Dudenhausen JW. HELLP syndrome. J Perinat Med. 2000. 28:249.

[4]. Lichtman, M, Kipps T, Seligsohn U, Kaushansky K, Prchal J. Hemolytic Anemia resulting from physical Injury to Red Cells. Williams Hematology, Eighth Edition. 8. McGraw-Hill Companies; 2010. Chapter 50.

[5]. Zhou Y, McMaster M, Woo K, et al. Vascular endothelial growth factor ligands and receptors that regulate human cytotrophoblast survival are dysregulated in severe preeclampsia and hemolysis, elevated liver enzymes, and low platelets syndrome. Am J Pathol. 2002. 160:1405-23

[6]. .6.Levine RJ, Maynard SE, Qian C, et al. Circulating angiogenic factors and the risk of preeclampsia. $N$ Engl J Med. 2004. 350:672. [Medline].

[7]. 7.Mutter WP, Karumanchi SA. Molecular mechanisms of preeclampsia. Microvasc Res. 2008. 75:1.[Medline]

[8]. 8.Widmer M, Villar J, Beniani A, et al. Mapping the theories of preeclampsia and the role of angiogenic factors: A systematic review. Obstet Gynecol 109:168, 2007. Obstet Gynecol. 2007. 109:168. [Medline].

[9]. 9. O'Brien JM, Barton JR. Controversies with the diagnosis and management of HELLP syndrome. Clinical Obstetrics and Gynecology. June 2005. 48:2:460-477.

[10]. 10.Sullivan CA, Magann EF, Perry KG Jr, et al. The recurrence risk of the syndrome of hemolysis, elevated liver enzymes, and low platelets: Subsequent pregnancy outcome and long term prognosis. Am J Obstet Gynecol. 1995. 172:125. 